\author{
Н. Р. Прокопчук, А. И. Глоба, И. О. Лаптик
}

Белорусский государственный технологический университет

\title{
МОДИФИКАЦИЯ НАНОАЛМАЗНЫМИ ЧАСТИЦАМИ ВОДНО-ДИСПЕРСИОННЫХ ГРУНТОВОК И ЭМАЛЕЙ
}

Исследована возможность улучшения технологических и эксплуатационных свойств покрытий на основе однокомпонентных водно-дисперсионных грунтовок и эмалей с помощью введения наноалмазных частиц. Осуществлена модификация лакокрасочных материалов наноразмерными добавками в количестве 0,005-0,100 мас. \%. Исследовано время высыхания и физикомеханические свойства однослойных покрытий из модифицированных лакокрасочных материалов (твердость, прочность при ударе, адгезия) на металлических подложках, а также оценены защитные свойства (стойкость к статическому воздействию воды, 3\%-ного раствора $\mathrm{NaCl}$, индустриального масла, дизельного топлива) покрытий на основе составов модифицированных грунтовок и эмалей с лучшими механическими свойствами. Покрытия получали в соответствии с технологиями, применяемыми на ЧУП «МАВ» (Республика Беларусь).

Ключевые слова: модификация, лакокрасочный материал, углеродные наноматериалы, алмазная шихта, ультрадисперсный алмаз, эмаль, грунтовка.

Для цитирования: Прокопчук Н. Р., Глоба А. И., Лаптик И. О. Модификация наноалмазными частицами водно-дисперсионных грунтовок и эмалей // Труды БГТУ. Сер. 2, Химические технологии, биотехнологии, геоэкология. 2021. № 1 (241). С. 114-119.

\section{N. R. Prokopchuk, A. I. Hloba, I. O. Laptik \\ Belarusian State Technological University \\ MODIFICATION WITH NANO-DIAMOND PARTICLES OF WATER-DISPERSIVE PRIMERS AND ENAMELS}

The possibility of improving the technological and operational properties of coatings based on single-component water-dispersion primers and enamel by introducing nanodiamond particles is investigated. The paint and varnish materials were modified with nanoscale additives in the amount of $0.005-0.100 \mathrm{wt} . \%$. The drying time and physical and mechanical properties of single-layer coatings made of modified paint and varnish materials (hardness, impact strength, adhesion) on metal substrates were studied, and the protective properties (resistance to static effects of water, $3 \% \mathrm{NaCl}$ solution, industrial oil, diesel fuel) of coatings based on modified primer and enamel compositions with the best mechanical properties were evaluated. The coatings were obtained in accordance with the technologies used by the private unitary enterprise "MAV" (Republic of Belarus).

Key words: modification, paint material, carbon nanomaterials, diamond charge, ultrafine diamond, enamel, primer.

For citation: Prokopchuk N. R., Hloba A I., Laptik I. O. Modification with nano-diamond particles of water dispersive primers and enamels. Proceedings of BSTU, issue 2, Chemical Engineering, Biotechnologies, Geoecology, 2021, no. 1 (241), pp. 114-119 (In Russian).

Введение. Развитие новой техники и технологий требует создания антикоррозионных покрытий с повышенной устойчивостью в температурно-силовых полях и агрессивных средах. Эту проблему экономически нецелесообразно решать только синтезом новых пленкообразующих веществ. Широкие перспективы открывают методы модификации, в том числе и наноразмерными частицами, промышленно выпускаемых грунтовок и эмалей [1]. Создание полимерных нанокомпозитов явилось важным достижением последних десятилетий. Нанокомпозит в своем составе содержит полимерную матрицу и дисперсный наноразмерный наполнитель. С уменьшением размера частиц возрастают удельная поверхность наполнителя, протяженность границы раздела, доля пограничного слоя. При размере частиц дисперсной фазы 10-100 нм композиционный материал относят к нанокомпозиту. В нем даже при содержании наночастиц порядка десятых долей процента практически весь полимер переходит в состояние граничного слоя.

Использование наноразмерных частиц в защитных лакокрасочных материалах (ЛКМ) весьма актуально, так как правильный выбор наномодификатора, его количества и способа введения может значительно улучшить эксплу- 
атационные свойства лакокрасочных покрытий практически без изменения технологий производства ЛКМ, получения покрытий и с минимальным увеличением стоимости $[2,3]$.

Наночастицы в лакокрасочных материалах находятся в связанной, суспензионной форме и поэтому технологии получения защитных покрытий безопасны [4]. Покрытия на основе наноразмерных композиций интенсивно изучаются в мире.

Например, изучено влияние функциональных групп латексных акриловых сополимеров на физико-механические свойства нанокомпозиционных покрытий с наполнителем из слоистого алюмосиликата [5].

Физической основой наномодифицирования являются потенциальные возможности субатомных частиц с высокой поверхностной энергией образовывать ионные и координационные связи, ограничивающие подвижность звеньев и сегментов макромолекул, проявлять когезионные и адгезионные взаимодействия и др.

Наноалмазы уже производятся в крупном промышленном масштабе, поэтому применяются в различных, чаще в термопластичных полярных матрицах. Частица наноалмаза состоит из упорядоченного кристаллического ядра и разрыхленной химически лабильной оболочки. Алмазное ядро - носитель основных «алмазных» свойств наноалмаза (термическая и химическая стабильность, твердость, высокая теплопроводность и низкая электропроводность). Оболочка наноалмаза ответственна за знак и величину поверхностного заряда частиц, абсорбцию, адсорбцию, хемосорбцию. Она играет решающую роль в процессах агрегации алмазных частиц и их взаимодействия с макромолекулами и функциональными добавками матрицы нанокомпозиционных наноматериалов и покрытий [6].

Цель исследования - оценка влияния углеродных наноматериалов на технологические и эксплуатационные свойства покрытий на основе однокомпонентных водно-дисперсионных лакокрасочных материалов.

Для достижения поставленной цели были решены следующие задачи:

- изготовлены суспензии углеродных наноматериалов (УНМ) различного состава;

- осуществлена модификация лакокрасочных материалов наноразмерными добавками в количестве $0,005,0,010,0,100 \%$ (в пересчете на массовую долю нелетучих веществ);

- нанесены модифицированные лакокрасочные материалы на подложки (сталь) и сформированы однослойные покрытия на их основе;

- исследовано время высыхания до третьей степени и физико-механические свойства однослойных покрытий на основе модифицированных лакокрасочных материалов (твердость, прочность при ударе, адгезия, эластичность при изгибе);

- оценены защитные свойства комплексных покрытий на основе лучших по механическим свойствам составов модифицированных лакокрасочных материалов (стойкость к статическому воздействию воды, $3 \%$-ного раствора $\mathrm{NaCl}$, индустриального масла, дизельного топлива);

- проведен сравнительный анализ модифицированных лакокрасочных материалов с выводами и рекомендациями.

Основная часть. В качестве объектов исследования были выбраны промышленно производимые на ЧУП «МАВ» грунтовка Belakor 02 и эмаль Belakor 12 (водные дисперсии акриловых сополимеров, пигментов, наполнителей, функциональных добавок, воды).

Belakor - система быстросохнущих лакокрасочных материалов для надежной защиты металлических поверхностей (железнодорожные подвижные составы, металлоконструкции, оборудование, механизмы и др.) с высокими физико-механическими показателями, эксплуатируемых в атмосферных условиях от -30 до $+50^{\circ} \mathrm{C}$ и для окраски внутри помещений при температуре не ниже $+5^{\circ} \mathrm{C}$.

Перед применением грунтовку и эмаль тщательно перемешивали и оставляли для удаления воздуха на 15-20 мин.

Время высыхания до третьей степени определяли в соответствии с ГОСТ 19007, твердость по маятниковому прибору типа ТМЛ маятник А - по ГОСТ 5233, прочность при ударе - по ГОСТ 4765 , адгезию методом решетчатых надрезов - по ГОСТ 15140.

Для определения времени высыхания и твердости покрытий испытуемые лакокрасочные материалы наносили на стекло размером $90 \times 120 \times 1,2$ мм. Для определения адгезии, прочности покрытий при ударе ЛКМ наносили на пластинки из стали марки 08кп размером $70 \times 150$ мм при толщине $0,8-0,9$ мм.

Для модификации грунтовки и эмали использовали углеродные наноматериалы производства НПЗАО «Синта» (Минск) - шихта алмазсодержащая марки АШ-А (ТУ РБ 100056180.003-2003) и алмаз синтетический ультрадисперсный УДА (ТУ РБ 28619110.001-95) (табл. 1).

Получение дисперсий наночастиц заключалось в диспергировании их в дисперсионной среде в ячейке ультразвуковой ванны Bandeline Sonorex в течение определенного времени. В качестве дисперсионной среды для АШ-А использовалась вода, хорошо совместимая с лакокрасочным материалом. Для смачивания наночастиц и облегчения процесса диспергирования, а также для стабилизации дисперсий вносился диспергатор Dispex Ultra 4480 на 
основе монофункционального блок-сополимера олеоалкиленоксида. Количество диспергатора, рекомендуемое производителем для диспергирования сажи при ее удельной поверхность 10 $60 \mathrm{~m}^{2} / \Gamma$, составляет примерно $50 \%$ от ее массы. Поэтому количество диспергатора рассчитывалось исходя из удельной поверхности нанодобавок. Так, для получения дисперсии на основе АШ-А вносилось 300\% диспергатора от массы частиц. Также использовали дисперсию на основе УДА в толуоле, полученную в производственных условиях из водного концентрата УДА-ВК путем замены водной фазы на органическую (толуол) для предотвращения агрегации и агломерации частиц синтетического ультрадисперсного алмаза в условиях получения сухого порошка.

Получали модифицированные лакокрасочные материалы, содержащие нанодабавки в концентрациях $0,005,0,010$ и 0,100 мас. \% в пересчете на сухой остаток, путем смешения грунтовки или эмали с дисперсией нанодобавки.

Из немодифицированных и полученных модифицированных лакокрасочных составов были сформированы однослойные покрытия на металлических подложках. Формирование покрытий из модифицированных составов осуществляли в соответствии с техническими требованиями к немодифицированным ЛКМ, соблюдая температурный режим, толщину покрытий и другие характеристики.

Покрытия определенной толщины отверждали в естественных условиях (грунтовка) и условиях горячей сушки (эмаль, $\left.80^{\circ} \mathrm{C}\right)$. Перед испытаниями образцы покрытий выдерживали 24 ч при комнатной температуре.

В табл. 2 представлены физико-механические свойства (твердость, прочность при ударе, адгезия) однослойных покрытий на основе модифицированных и немодифицированных лакокрасочных материалов.

Из табл. 2 видно, что через 3 сут после высыхания твердость покрытий после модификации алмазосодержащими добавками стала лучше. Через продолжительное время (после 30 сут) формирования покрытия после завершения всех химических и физических процессов в нем твердость всех покрытий значительно увеличилась, примерно на 0,1-0,2 отн. ед. После окончательного формирования покрытий твердость их для образцов № 2-7 выше твердости немодифицированных покрытий (на 20\%). Наивысшей твердостью характеризуются покрытия на основе грунтовки Belakor 02, модифицированной АШ-А в количестве $0,01 \%$,0,50 отн. ед.

Анализ данных табл. 2 показывает: адгезия покрытий к стали изменяется с 2 до 1 балла уже при содержании наноалмазных частиц 0,005 мас. \%. Дальнейшее увеличение содержания наночастиц как в грунтовке, так и в эмали не влияет на адгезию. Прочность при ударе вначале возрастает с 90 до 100 см (на 11\%) при введении 0,005 мас. \% наночастиц, а затем остается постоянной. Твердость покрытий возрастает во времени. Покрытие окончательно структурируется через 30 сут, поэтому анализируются максимально достижимые значения твердости. Твердость грунтовки с наночастицами АШ-А максимальная при концентрации 0,01 мас. \% (возрастает с 0,31 до 0,42 отн. ед., т. е. на $35 \%$ ). Наночастицы с УДА увеличивают твердость покрытий несколько больше (с 0,31 до 0,45 отн. ед., т. е. на 45\%) при той же концентрации 0,01 мас. \%.

Твердость эмали при модификации наночастицами изменяется следующим образом. Введение АШ-А в количестве 0,005 мас. \% повышает твердость с 0,36 до 0,56 отн. ед. (т. е. на $56 \%$ ), а введение УДА в количестве 0,01 мас. \% - с 0,36 до 0,60 отн. ед. (т. е. на $67 \%$ грунтовки и эмали). Более эффективным модификатором эмали по показателю «твердость» являются наночастицы УДА по сравнению с наночастицами АШ-А.

Таблица 1

Характеристика углеродных наноматериалов

\begin{tabular}{|c|c|c|}
\hline Наименование показателя & АШ-А & УДА \\
\hline Метод получения & Детонационный синтез & Химическая очистка АШ-В \\
\hline Внешний вид & Черный порошок & Серый порошок \\
\hline Размер и форма & \begin{tabular}{|l|} 
Полидисперсный порошок (1-100 мкм) с \\
неправильными частицами округлой формы
\end{tabular} & $\begin{array}{l}\text { Полидисперсные порошки: 30; } \\
40 ; 90 ; 100 ; 700 ; 900 \text { нм со } \\
\text { сферическими частицами }\end{array}$ \\
\hline Размер единичного кристалла, нм & 10 & $4-6$ \\
\hline Окисляемые формы углерода, \% & 53,4 & 1,2 \\
\hline Удельная поверхность, м²/г & 404 & 295 \\
\hline Объем пор, см $^{3} / \Gamma$ & 1,245 & 0,84 \\
\hline $\begin{array}{l}\text { Функциональные поверхност- } \\
\text { ные группы }\end{array}$ & $\mathrm{COOH}, \mathrm{CH}_{x}, \mathrm{C}_{6} \mathrm{X}_{6}$ & $\begin{array}{c}\mathrm{COOH}, \mathrm{COOR}, \mathrm{CH}_{x}, \mathrm{C}-\mathrm{N}, \\
\mathrm{C}=\mathrm{N}, \mathrm{C}-\mathrm{O}-\mathrm{O}, \mathrm{OH}, \mathrm{CO}\end{array}$ \\
\hline
\end{tabular}

Труды БГТУ Серия 2 № 12021 
Физико-механические свойства ЛКМ, модифицированные наноматериалами

Таблица 2

\begin{tabular}{|c|c|c|c|c|c|}
\hline $\begin{array}{c}\text { Номер } \\
\text { образца }\end{array}$ & $\begin{array}{c}\text { Количество } \\
\text { наноматериала, \% }\end{array}$ & Тип модификатора & $\begin{array}{c}\text { Адгезия, } \\
\text { балл }\end{array}$ & $\begin{array}{c}\text { Прочность } \\
\text { при ударе, см }\end{array}$ & $\begin{array}{c}\text { Твердость, отн. ед. через } \\
30 \text { сут после нанесения }\end{array}$ \\
\hline
\end{tabular}

\begin{tabular}{|c|c|c|c|c|c|}
\hline \multicolumn{7}{|c|}{ Belakor 02 } \\
\hline 1 & - & - & 2 & 90 & 0,31 \\
\hline 2 & 0,005 & АШ-A & 1 & 100 & 0,38 \\
\hline 3 & 0,01 & АШ-А & 1 & 100 & 0,42 \\
\hline 4 & 0,1 & АШ-A & 1 & 100 & 0,40 \\
\hline 5 & 0,005 & УДА & 1 & 100 & 0,37 \\
\hline 6 & 0,01 & УДА & 1 & 100 & 0,45 \\
\hline 7 & 0,1 & УДА & 1 & 100 & 0,43 \\
\hline \multicolumn{7}{|c|}{ Belakor 12} \\
\hline 8 & - & - & 2 & 90 & 0,36 \\
\hline 9 & 0,005 & АШ-А & 1 & 100 & 0,56 \\
\hline 10 & 0,01 & АШ-А & 1 & 100 & 0,36 \\
\hline 11 & 0,1 & АШ-А & 1 & 100 & 0,55 \\
\hline 12 & 0,005 & УДА & 1 & 100 & 0,55 \\
\hline 13 & 0,01 & УДА & 1 & 100 & 0,60 \\
\hline 14 & 0,1 & УДА & 1 & 100 & 0,60 \\
\hline
\end{tabular}

Из всех исследуемых образцов наилучшими свойствами обладают АШ-А $(0,01 \%)$, УДА $(0,01 \%)$ и УДА $(0,1 \%)$. Для этих образцов определяли время высыхания до третьей степени по ГОСТ 19007 (рис. 1).

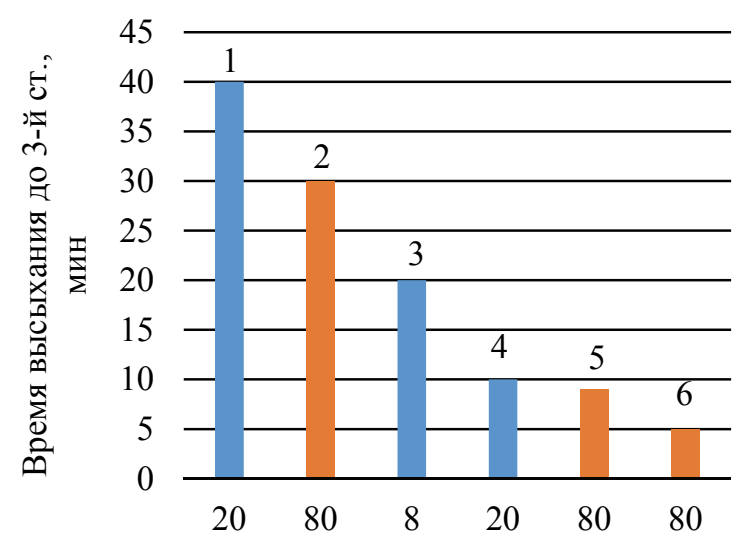

Температура, ${ }^{\circ} \mathrm{C}$

Рис. 1. Зависимость времени высыхания от температуры:

1 - АШ-А (грунтовка $0 \%$ при $20^{\circ} \mathrm{C}$ ); 2 - УДА (эмаль $0 \%$ при $80^{\circ} \mathrm{C}$ );

3 - АШ-А (грунтовка $0,01 \%$ при $8^{\circ} \mathrm{C}$ );

4 - АШ-А (грунтовка $0,01 \%$ при $20^{\circ} \mathrm{C}$ ); 5 - УДА (эмаль $0,1 \%$ при $80^{\circ} \mathrm{C}$ ); 6 - УДА (эмаль $0,01 \%$ при $80^{\circ} \mathrm{C}$ )

Из диаграммы видно, что существенно снижается время отверждения грунтовки и эмали, модифицированных наноалмазными частицами. Так, при концентрации УДА 0,01 мас. \% время отверждения до 3-й степени составило 9 мин, а при концентрации УДА 0,1 мас. \% 5 мин (нулевая точка $(0 \%)$ равна 30 мин при $\left.80^{\circ} \mathrm{C}\right)$. При концентрации АШ-А 0,01 мас. \% и температуре $20^{\circ} \mathrm{C}$ время отверждения достигло 10 мин, а при концентрации АШ-А 0,01 мас. \% и температуре $8^{\circ} \mathrm{C}$ время отверждения составило 20 мин (нулевая точка (0\%) равна 40 мин при естественной сушке). Существенное снижение времени отверждения грунтовки и эмали наноалмазными частицами можно связать с образованием ими физической сетки, пронизывающей макромолекулы акриловых сополимеров. Сетка способствует вытеснению воды из формирующихся покрытий. Чем выше концентрация наночастиц, тем плотнее сетка и быстрее вытесняется вода. Это важно с точки зрения энергосбережения и повышения производительности процесса при производстве защитных покрытий по стали.

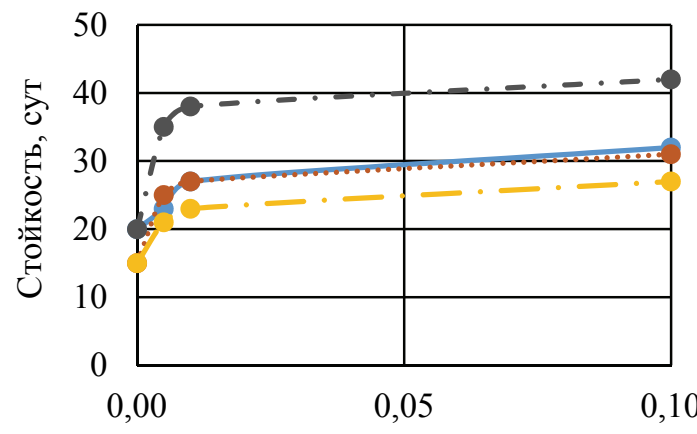

Концентрация модификатора, \%

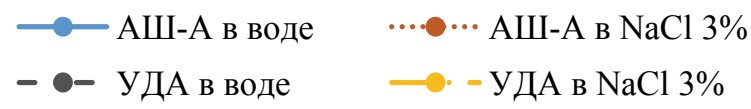

Рис. 2. Стойкость покрытия к статическому воздействию агрессивных сред для грунтовки Belakor 02 при $(20 \pm 2)^{\circ} \mathrm{C}$, сут 


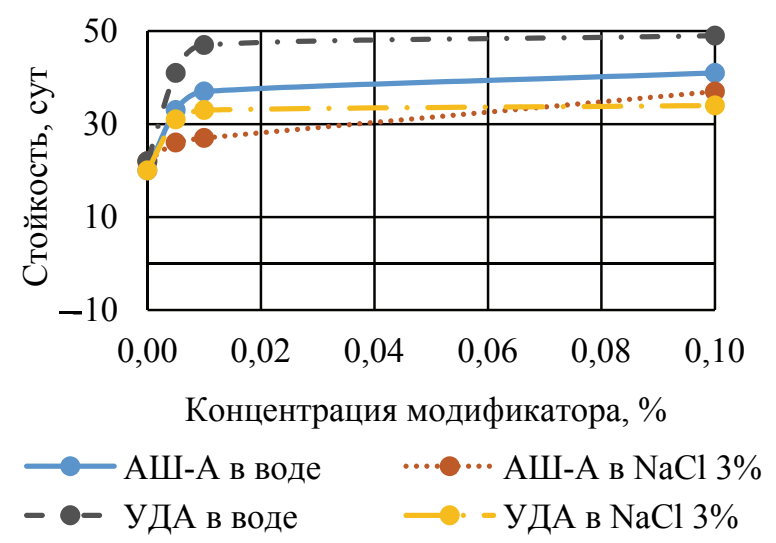

Рис. 3. Стойкость покрытия к статическому воздействию агрессивных сред

для эмали Belakor 12 при $(20 \pm 2)^{\circ} \mathrm{C}$, сут

Стойкость грунтовки и эмали к статическому воздействию воды и $3 \%$-ного $\mathrm{NaCl}$ (рис. 2, 3) значительно возрастает при содержании в них модификаторов АШ-А и УДА. Водостойкость грунтовки возрастает с 20 до 32 сут при содержании в ней 0,1 мас. \% АШ-А (на 60\%). При модификации УДА водостойкость возрастает еще больше (с 20 до 42 сут, т. е. на $110 \%$ ). Стойкость эмали к действию воды еще больше возрастает при наномодификации: при введении 0,1 мас. \% АШ-А с 20 до 37 сут (на 85\%), а 0,1 мас. \% УДА с 20 до 49 сут (на 145\%).
Установленный факт имеет важное практическое значение. Зависимость стойкости к статическому воздействию $3 \%$-ного раствора $\mathrm{NaCl}$ от природы и содержания наноалмазных частиц аналогична зависимости водостойкости. Наночастицы УДА более эффективно, чем АШ-А, повышают стойкость к 3\%-ному раствору $\mathrm{NaCl}$ как грунтовки, так и эмали. Установлено существенное повышение устойчивости в силовых полях и агрессивных средах покрытий по стали на основе воднодисперсионных ЛКМ (грунтовка Belakor 02 и эмаль Belakor 12 производства ЧУП «МАВ»), модифицированных наноалмазными частицами АШ-А и УДА производства НПЗАО «Синта» (г. Минск).

Заключение. Наночастицы, распределившись по всему объему покрытий и взаимодействуя друг с другом, образуют физическую сетку, усиливающую межмолекулярные взаимодействия между цепочками акриловых сополимеров. Модифицированная наноалмазными частицами надмолекулярная структура грунтовки и эмали на металлической подложке представляет собой систему взаимопроникающих сеток, которая существенно повышает важные в практическом значении показатели: адгезию, прочность при ударе, твердость, стойкость к статическому воздействию воды и $3 \%$-ного $\mathrm{NaCl}$.

\section{Список литературы}

1. Стокозенко В. Н. Нанотехнологии сегодня и завтра // Промышленная окраска. 2006. № 3. C. 22-24.

2. Шашок Ж. С. Прокопчук Н. Р. Применение углеродных наноматериалов в полимерных композициях. Минск: БГТУ, 2014. 232 с.

3. Долматов В. Ю. Ультрадисперсные алмазы детонационного синтеза. Получение, свойства, применение: монография. СПб.: Изд-во СПбГПУ, 2003. 344 с.

4. Зубилевич, М., Гнот В. Антикорозионные лакокрасочные материалы нового поколения // Лакокрасочные материалы и их применение. 2005. № 6. С. 7-11.

5. Агафонов, Г. И., Дринберг А. С., Ицко Э. Ф. Использование нанотехнологий в лакокрасочных материалах // Лакокрасочные материалы и их применение. 2007. № 4. С. 10-14.

6. Верхоланцев В. В. Наноматериалы в технологии лакокрасочных покрытий // Лакокрасочные материалы и их применение. 2004. № 10. С. 20-23.

\section{References}

1. Stokozenko V. N. Nanotechnology today and tomorrow. Promyshlennaya okraska [Industrial painting], 2006, no. 3, pp. 22-24 (In Russian).

2. Shashok Zh. S., Prokopchuk N., R. Primeneniye nanomaterialov v polimernykh kompozitsionnykh materialakh [The use of carbon nanomaterials in polymer compositions], Minsk, BGTU Publ., 2014. 232 p.

3. Dolmatov V. Yu. Ul'tradispersnyye almazy detonatsionnogo sinteza. Polucheniye, svoystva, primeneniye: monografiya [Ultrafine detonation synthesis diamonds. Obtaining, properties, application: monograph], SPb., SPbGPU Publ., 2003. 344 p.

4. Zubilevich M., Gnot V. New generation anti-corrosion paints and varnishes. Lakokrasochnyye materialy $i$ ikh primeneniye [Paints and varnishes and their application], 2005, no. 6, pp. 7-11 (In Russian).

5. Agafonov G. I., Drinberg A. S., Itsko E. F. The use of nanotechnology in paints and varnishes. Lakokrasochnyye materialy $i$ ikh primeneniye [Paints and varnishes and their application], 2007, no. 4, pp. 10-14 (In Russian). 
6. Verkholantsev V. V. Nanomaterials in paint and varnish technology. Lakokrasochnyye materialy $i$ ikh primeneniye [Paints and varnishes and their application], 2004, no. 10, pp. 20-23 (In Russian).

\section{Информация об авторах}

Прокопчук Николай Романович - член-корреспондент Национальной академии наук Беларуси, доктор химических наук, профессор, профессор кафедры полимерных композиционных материалов. Белорусский государственный технологический университет (220006, г. Минск, ул. Свердлова, 13a, Республика Беларусь). E-mail: tnsippm@belstu.by

Глоба Анастасия Ивановна - кандидат химических наук, доцент кафедры полимерных композиционных материалов. Белорусский государственный технологический университет (220006, г. Минск, ул. Свердлова, 13а, Республика Беларусь). E-mail: Orion-2308@yandex.ru

Лаптик Инна Олеговна - инженер кафедры полимерных композиционных материалов. Белорусский государственный технологический университет (220006, г. Минск, ул. Свердлова, 13a, Республика Беларусь). E-mail: inna.laptik@yandex.ru

\section{Information about the authors}

Prokopchuk Nikolay Romanovich - Corresponding Member of the National Academy of Sciences of Belarus, DSc (Chemistry), Professor, Professor of the Department of Polymer Composite Materials. Belarusian State Technological University (13a, Sverdlova str., 220006, Minsk, Republic of Belarus). E-mail: tnsippm@belstu.by

Hloba Nastassia Ivanovna - PhD (Chemistry), Assistant Professor, the Department of Polymer Composite Materials. Belarusian State Technological University (13a, Sverdlova str., 220006, Minsk, Republic of Belarus). E-mail: Orion-2308@yandex.ru

Laptik Inna Olegovna - engineer, the Department of Polymer Composite Materials. Belarusian State Technological University (13a, Sverdlova str., 220006, Minsk, Republic of Belarus). E-mail: inna.laptik@yandex.ru 